REVISTA CHILENA DE LITERATURA

Abril 2009, Número 74, 57 - 78

\title{
JOAQUÍN EDWARDS BELLO: CRÓNICA Y CRÍTICA DE LA VIDA COTIDIANA CHILENA
}

\author{
Leonidas Morales T. \\ Universidad de Chile \\ lmoralest@vtr.net
}

RESUMEN / ABSTRACT

Si bien el objeto central del artículo es la crítica a la vida cotidiana chilena en Joaquín Edwards Bello, en su primera parte se detiene en algunos aspectos importantes del género en que la crítica se da, la crónica urbana, asociados a su origen periodístico, a su estructura, a su lector y al estado de la modernidad chilena que su irrupción a comienzos del XX implica. En la segunda parte, y sobre la base de un breve corpus cronístico, el artículo intenta definir lo esencial de la crítica de Edwards como una crítica a un modo específico (no interrumpido desde la Colonia) de ejercerse el poder en la sociedad chilena, uno de extrema polarización, y a los discursos ideológicos que le prestan la cobertura de su "naturalización".

PALABRAS ClAVE: crónica, periodismo, moderno, poder, ideología.

This article focuses on the criticism of Chilean everyday life in the writings of Joaquin Edwards Bello. The first part concentrates on important aspects of urban chronicle as a genre associated to its journalistic origin, structure, readership, and the conditions of Chilean modernity at the beginning of the 20th century. Supported by a brief corpus of chronicles, the second part of the article attempts to define one essential feature present in Edwards's criticism: namely a criticism of both a specific and uninterrupted mode in which power has been imposed on the Chilean society effecting extreme forms of polarization and the ideological discourses that "naturalize" its presence.

KEY WORDS: chronicle, journalism, modern, power, ideology.

" Este ensayo forma parte de un proyecto de investigación ( $\left.{ }^{\circ} 1061203\right)$, "Crítica de la vida cotidiana chilena. Carta, crónica, diario íntimo", aprobado y financiado por FONDECYT. 


\section{JOAQUÍN EDWARDS, EDITADO}

El primer libro de Joaquín Edwards Bello (1887-1968) fue una novela: El inútil, de 1910. Publicaría otras en años posteriores ${ }^{1}$. Algunas incluso han tenido reediciones, como El roto y Vaparaíso, ciudad del viento. Pero aun cuando no son para nada ajenas, al contrario, a los temas de este ensayo, mi corpus de textos de referencia responde, en su composición, a una opción que las excluye desde el punto de vista del género. En efecto, el corpus solo contempla textos pertenecientes al género que Edwards cultivó de manera ininterrumpida a lo largo de medio siglo: el de la crónica, o mejor, de la crónica urbana, que es como la nombramos hoy. Los textos cronísticos elegidos lo han sido desde luego en función de los temas de que se ocupa este ensayo. El principal es recurrente en las crónicas de Edwards, desde el comienzo: la crítica de la vida cotidiana chilena. Edwards vuelve una y otra vez a ella, como si no pudiera evitarlo, como si el retorno de su ejercicio fuera inseparable de su percepción misma de la vida cotidiana chilena. A veces, la crítica es compasiva y suele presentarse entonces bajo forma humorística, pero a veces también se abre, con menos indulgencia, con tonos más sombríos, a todo un complejo de deformaciones culturales, éticas, políticas, que esa cotidianeidad escenifica. Nunca las crónicas "esencializan" su pensamiento: lo sitúan siempre en una perspectiva histórica.

Hay algunas restricciones y algunas libertades que este ensayo se impone o se da con respecto a sus temas. Restricciones: no haré aquí ningún examen minucioso, con pretensiones de exhaustividad, de la crítica de Edwards a la vida cotidiana chilena. En otras palabras, no seguiré sus alternativas, por ejemplo, a través de un amplio corpus de textos cronísticos. Aun más: me limitaré, en lo fundamental, a uno solo de sus episodios y a su contexto histórico. No se trata, por supuesto, de un episodio menor, de rango jerárquico secundario dentro del universo crítico al que pertenece. Tiene más bien una significación estratégica: sus elementos discursivos permiten construir un orden de ideas, o de pensamiento, con las propiedades de un marco de inteligibilidad, dentro del cual, o desde el cual, es posible determinar, o captar, el sentido y la orientación de los diversos momentos de la crítica de Edwards.

1 El monstruo (1912), La cuna de Esmeraldo (1918), El roto (1920), El chileno en Madrid (1928), Valparaíso, la ciudad del viento (1931), Criollos en París (1933), La chica del Crillón (1935). 
Libertades: no voy a entrar de inmediato en el ámbito textual de tal episodio crítico. Me detendré antes en algunos aspectos que normalmente se omiten cuando se habla de Edwards como cronista: los problemas de edición que plantean las compilaciones conocidas de sus crónicas, las condiciones históricas de posibilidad de la crónica como género, el momento de la historia de la sociedad chilena en que irrumpen las de Joaquín Edwards y la excepcionalmente lúcida conciencia que éste tenía de la crónica desde el punto de vista de su relación con el tiempo de lo cotidiano moderno.

No está demás reiterar (legitimando desde otro ángulo la reducción del corpus al género de la crónica) un hecho de valoración literaria consolidado por la recepción crítica, al menos en la chilena: son sus crónicas las que han cimentado el prestigio actual de Joaquín Edwards como escritor, hasta el punto de que su nombre sea en Chile casi sinónimo de cronista. El volumen de su producción cronística, de dimensiones verdaderamente apabullantes, habla, más que de una voluntad sostenida de escritura, expresada en su continuidad, de una necesidad casi compulsiva de la misma, una escritura portadora de una tensión subterránea que, de pronto, algunas frases particularmente felices por su carga de sentido, dejan presentir o simplemente sacan a la superficie. Un fenómeno éste, el de la compulsión, para nada inusual en la literatura moderna, incluyendo la de Chile. Por ejemplo, dentro de otro momento histórico, comprometiendo otros géneros literarios y asociado a otra problemática cultural, literaria y social, el mismo gesto compulsivo y la misma tensión subyacente se repetirán en Roberto Bolaño.

Varias colecciones de crónicas de Edwards se publicaron mientras él vivía $^{2}$. Pero muchas otras han venido apareciendo después de su muerte ${ }^{3}$. Casi todas estas últimas, y algunas del período anterior, han sido producto del trabajo de Alfonso Calderón, compilador incansable y, en esta tarea, gestor importante de la difusión de las crónicas de Edwards. Pero todas estas colecciones presentan un mismo problema de edición que con el tiempo se

2 Tres meses en Río de Janeiro (1911), Crónicas (1924), El nacionalismo continental (1925), El bombardeo de Valparaíso y su época (1934), Don Eliodoro Yáñez, La Nación y otros ensayos (1934), Crónicas (1964), Nuevas crónicas (1966), Hotel Oddó (1966), El subterráneo de los jesuitas y otros mitos (1966).

3 Por ejemplo, Andando por Madrid y otras páginas (1969), En torno al periodismo y otros asuntos (1969), La Quintrala, Portales y algo más (1969), El Marqués de Cuevas (1974), La deschilenización de Chile (1977), La novela de Balmaceda (1981), Homo chilensis (1983). 
ha agravado. Ya se advertía en las anteriores a 1968, año de la muerte de Edwards, la tendencia a no registrar ni la fecha ni el nombre del periódico o revista donde pudieron haberse publicado originalmente cada una de las crónicas incluidas, o si ellas fueron escritas para ese libro expresamente. La tendencia se vuelve sistemática en las colecciones publicadas después de 1968, una omisión importante para quien quiera estudiar estas crónicas con los criterios de un estética textual, para la cual no es indiferente ni el medio ni la fecha de la primera publicación, y menos, tratándose de un género como la crónica urbana, tributaria precisamente de la más estricta puntualidad en este sentido. Esta tendencia de las compilaciones a borrar las marcas de origen de los textos, que son asimismo las de su historia, privilegiando el efecto de composición "unitaria" de los conjuntos, alcanza momentos particularmente difíciles de aceptar, desde el punto de vista de una crítica rigurosa, en dos libros recientes. Ambos se proponen sin embargo un objetivo legítimo, oportuno también, como lo es rescatar, para ofrecérselos al lector de hoy, textos de Edwards de difícil acceso por el tiempo transcurrido desde que se publicaron por primera vez en diarios o revistas.

Uno de estos dos libros, de 2005, es el de Cecilia García-Huidobro, Joaquín Edwards Bello. Un transatlántico varado en Santiago, destinado a reunir las escasas entrevistas dadas por Edwards, reacio, se sabe, a concederlas. La compiladora distribuye las entrevistas en cuatro períodos. Aun cuando indica la procedencia de las entrevistas (quién la hizo, fecha y medio donde se publicó), no hace lo mismo en la introducción, o "prefacio", a cada uno de los cuatro grupos. Construye estas introducciones usando fragmentos de crónicas de Edwards, reproducidos literalmente pero sin ponerlos entre comillas y sin especificar, en una nota a pie de página, de qué crónica provienen exactamente (solo indica las fuentes utilizadas). Y lo peor: intenta darles continuidad a estos fragmentos intercalando entre ellos frases suyas, escritas en un estilo neutro y puestas en cursiva para diferenciarlas, que tendrían como función simular la presencia de un intermediario entre los fragmentos, de modo que el montaje sea recepcionado por el lector como una suerte de entrevista... Construye los "prefacios" de esta manera para, dice, "reforzar el carácter autobiográfico que este volumen tiene" (20).

El segundo libro, Crónicas reunidas (I) 1921-1925, publicado el año 2008 en una edición de Roberto Merino, aparece como el primer tomo de una serie concebida para "reunir" la "casi” totalidad de las crónicas de Edwards. Esta primera compilación repite déficits de edición ya señalados. En su prólogo, Roberto Merino informa que las crónicas incluidas se publicaron 
originalmente en dos periódicos, La Nación y Los Tiempos, pero, en su edición, encabezando el texto de cada una solo se da la fecha de publicación, y no la especificación de en cuál de los periódicos apareció. Tratándose de un libro de producción universitaria, pudieron incorporarse algunas notas a pie de página con información necesaria para lectores interesados en estudiar las crónicas de Edwards y sus temas. Información, por ejemplo, sobre aquellas que ya habían sido recogidas en libro. Un caso: de la crónica "Recuerdos de Teresa Wilms" (149-152), se consigna desde luego su fecha: 21 de diciembre de 1921, pero el lector se queda sin saber que ésta había sido ya seleccionada y publicada por el propio autor, con el título de "Teresa Wilms y el Marqués de Bradomin”, en su libro Crónicas (192-195), de 1924, y, lo más relevante, que entre ambos textos hay diferencias de escritura en los párrafos de comienzo y de final. Por último, discutibles son también los criterios de edición enunciados por Merino al final de su prólogo (12-13): son criterios según los cuales modifica, con argumentos de fácil refutación, algunos usos de lenguaje de la escritura original, borrando así sus connotaciones culturales, históricas, incluso biográficas. Por ejemplo, ¿por qué "castellanizar" (aunque con el tiempo la práctica de la lengua así lo haya hecho) palabras escritas por el autor en su lengua de origen, como "chauffeur", que queda en "chofer"? ¿Acaso se ignora que todavía en la década de 1920 el francés seguía siendo la lengua de la cultura, como lo había sido en el siglo anterior, cuando París, según Benjamin, era la "capital del siglo XIX", y que citarla era un gesto tanto de reconocimiento como de participación?

Lo que queda a la vista, me parece, es la inexistencia en Chile, por lo menos a nivel de los medios y de cierta cultura pública, de una tradición reconocida y asentada de "editor", es decir, de quien prepara textos para su publicación bajo reglas que suponen un saber teórico acerca de la naturaleza de los textos (su género, etc.) que están en juego, del que se derivan también determinadas responsabilidades. La figura del editor de textos, instalada y prestigiada en los espacios académicos de otros países, sobre todo entre aquellos de una cultura moderna del texto más desarrollada, pero que tampoco ha estado siempre ausente del todo en nuestros propios espacios académicos ${ }^{4}$, hoy, en el campo de la cultura pública chilena, administrada de manera absorbente por los medios de comunicación masiva, incluidas las

4 Un caso ejemplar de editor de textos en Chile ha sido Alfonso Escudero. 
editoriales, solo existe como vacío, ausencia, o, lo que viene a ser lo mismo, como desfiguración de su función. Pareciera que, entre nosotros, hay lugar hasta ahora para el autor y la editorial como únicos agentes de la producción y circulación de libros. Quienes asumen la tarea de editor de textos suelen moverse por lo mismo en una zona franca, que al no estar regulada, les permite "licencias" como las denunciadas más arriba a propósito de las compilaciones de crónicas de Edwards ${ }^{5}$.

\section{GÉNERO Y RECEPCIÓN CRÍTICA}

¿Y la recepción crítica de la producción cronística de Edwards? A pesar de que el nombre de este escritor es casi una institución dentro de la cultura literaria chilena, la mayor parte de la bibliografía crítica acumulada en torno a él, no menor en cantidad de títulos, se concentra en el tópico de la "identificación entre el hombre y su obra", en palabras de Milton Rossel, para quien "pocas veces se ha dado en nuestras letras un ejemplo mayor" que el ofrecido por Edwards (Rossel 5). En efecto, la personalidad cultural de este escritor, poco común, intelectualmente seductora, atípica, por su libertad, en un país como Chile, más dotado para producir vidas regladas (o reguladas, y regulares), es lo que se focaliza habitualmente en artículos o en entrevistas (pocas, dada la resistencia de Edwards a concederlas). De esta parte de la bibliografía quedan algunas imágenes biográficas sugerentes, de significado todavía por construir como significado crítico, pero potencialmente rico, y algunos juicios luminosos sobre periodistas, periodismo y crónica, emitidos por el autor en el curso de alguna entrevista. De esta bibliografía están ausentes, en general, cuestiones que hoy nos resultan no solo de interés sino apasionantes, como: el lugar de las crónicas de Edwards en la historia chilena y latinoamericana del género, las relaciones históricas entre crónica y periodismo, la percepción del tiempo, como tiempo de la modernidad, en las crónicas de Edwards.

5 Una anécdota reveladora de lo que planteo: en 1995, después de varios años de trabajo (y sin apoyo económico institucional) con los materiales textuales conservados del diario de vida de Luis Oyarzún, quien había muerto en 1972, pude publicar mi edición crítica de este diario, pieza fundamental de la cultura literaria chilena, con el título de Diario íntimo. En el mismo año, recibió el Premio Municipal. A la entrega oficial del premio fueron invitados los herederos de Luis Oyarzún, pero al editor de su diario, sin el cual no se hubiera publicado, ni siquiera se le informó. 
Tal vez dos hechos contribuyan a explicar estas ausencias. Uno: la tardía introducción (década de 1990) en los espacios académicos chilenos como centros de irradiación, del interés teórico y crítico por las clases de géneros discursivos a las que pertenece la crónica urbana, géneros de no ficción o referenciales (junto con la crónica, la carta, el diario íntimo, la autobiografía, etc.). Dos: la también tardía sensibilización crítica (contemporánea de la globalización posmoderna) frente a la historia de la modernidad chilena, a sus singularidades y a sus diferentes fases.

Desde la perspectiva de la crítica de la vida cotidiana chilena asociada a la historia de la modernidad, y dentro desde luego del universo de los géneros referenciales, las cartas de amor de Carmen Arriagada (décadas de 1830 a 1850) representan el momento más interesante y seductor de esta crítica en el siglo XIX, por sus implicaciones culturales, literarias, históricas, de género sexual. Ahora bien, desplazar la mirada desde Carmen Arriagada a Joaquín Edwards no solo significa ir, en términos discursivos, de un género a otro (de la carta a la crónica urbana), o, en términos culturales, del gesto romántico a otro inserto ya en el siglo $\mathrm{XX}$ y en un horizonte próximo de nuestra contemporaneidad, sino pasar, en la perspectiva de las peripecias históricas de nuestra modernidad, de las ausencias a las presencias como experiencias cotidianas del tiempo. Desde el término de la Independencia y el afianzamiento de la República, y a lo largo de la segunda mitad del siglo XIX, fue formándose la nueva burguesía chilena mediante la alianza entre la antigua aristocracia de la tierra y jóvenes extranjeros (europeos -ingleses sobre todo- y norteameamericanos) que con la expansión neocolonialista producida en ese siglo llegan como agentes comerciales, como profesionales contratados por el gobierno dentro de los proyectos modernizadores de la nueva República, o como artistas o intelectuales buscando en América lo que la modernidad en su avance ha convertido en memoria. Alianzas bajo la forma del matrimonio, o de sociedades comerciales, o de ambas a la vez ${ }^{6}$. Carmen Arriagada se había casado con un oficial alemán contratado por el gobierno chileno. El apellido de nuestro cronista no es justamente hispánico: "Edwards".

6 Sobre esta nueva burguesía, véase Sergio Villalobos, Origen y ascenso de la burguesía chilena. Santiago, Editorial Universitaria, 1998 ( $4^{\mathrm{a}} \mathrm{ed}$.). 
La formación de la nueva burguesía chilena no es otra cosa que el proceso de tránsito (o de recomposición) de las formas del poder (político, económico, cultural), desde un paradigma colonial a un paradigma moderno, sin que ello signifique la desaparición de constantes "estructurales" asociadas a los orígenes y la historia del poder en Chile (a las que más adelante me referiré con el nombre ya acuñado en Chile desde Portales, y que Joaquín Edwards evoca: el "peso de la noche"). Puesto que decir "modernidad" supone decir al mismo tiempo "ciudad", "espacio urbano", el proceso de formación y gestión de la nueva burguesía es por supuesto simultáneo con otro: el de la transformación de la ciudad "patricia" (la de los años de las cartas de amor de Carmen Arriagada a Rugendas), en la ciudad "burguesa", usando la nomenclatura de José Luis Romero ${ }^{7}$. Lo que no había en 1830 ó 1840, ya lo está en las dos últimas décadas del siglo y, sobre todo, en las primeras del XX: la calle como espacio intransitivo (finalidad en sí misma), escenario público por excelencia de la vida cotidiana moderna. La ciudad comienza a ser lo que toda ciudad moderna comienza siendo: el lugar donde o desde donde se configura el deseo como expectativa de felicidad. Esta ciudad y esta calle son supuestos biográficos y culturales (están ya ahí) de las crónicas de Edwards.

Pero no solo ellas. Hay otro supuesto que condiciona de una manera más radical, como género mismo, a esas crónicas. Me refiero al periódico. Los periódicos son igualmente soportes, "dispositivos" inseparables de modernidad. En Chile, y en toda América Latina, su aparición y el modo de su desarrollo marcan, a su manera, los ritmos de las modernizaciones de las nuevas "naciones" en el terreno de lo que Benedict Anderson llama el "capital impreso". En Estados Unidos, los periódicos desde el comienzo establecen una suerte de lazo funcional solidario con el comercio, la publicidad, el avisaje (Anderson 97), vínculo que, desde luego, los periódicos latinoamericanos repetirán. En Chile, por ejemplo, es el caso de El Mercurio, fundado en Valparaíso en 1827, el único de los surgidos en esos años que se mantiene hasta hoy. Muchos periódicos se publicaron en el siglo XIX (El Araucano, El Ferrocarril, etc.), cada uno con su propio proyecto, pero todos, al final, de

7 José Luis Romero, Latinoamérica. Las ciudades y las ideas. Buenos Aires, Siglo XXI Editores, 2004 ( $1^{\mathrm{a}}$ ed., 1976). 
corta vida ${ }^{8}$. En todo caso, si se toma como tramo cronológico de referencia las dos últimas décadas del siglo XIX, las más importantes por la concentración de modernidad cotidiana que en ellas se produce, los periódicos que entonces se publican en Chile suman una cantidad muy menor, comparada con la que en el mismo período se publican en Argentina ${ }^{9}$, lo que sin duda marca una diferencia desde el punto de vista del desarrollo de la modernidad a nivel de la cultura impresa de los medios. De esas décadas finales de siglo, los periódicos más importantes de América Latina son La Nación de Buenos Aires y La Opinión Nacional de Caracas, justamente donde José Martí publicaba las que serían las primeras crónicas urbanas latinoamericanas.

Junto con la mutiplicación de los periódicos, con sus cambios de formato y composición interna, nunca ajenos a los cambios paralelos en la cultura cotidiana moderna, a las etapas o momentos de su desarrollo, van apareciendo los diversos géneros periodísticos. Si bien la función del periódico es ofrecer "noticias", las formas de la noticia y los modos discursivos de elaborarla y entregarla son variados. Esta variedad tiene que ver precisamente con los géneros, que son muchísimos, desde el más simple, la breve información de un hecho (cualquiera sea su naturaleza), hasta aquellos de mayor extensión y despliegue narrativo, incluyendo, con fines comerciales, de venta, hasta ficciones narrativas. Por ejemplo, el folletín, de origen francés, difundido sobre todo a partir de la 1840 con Los misterios de París, de Eugenio Sue, uno de los grandes éxitos literario-comerciales del periodismo. También los periódicos latinoamericanos publicaron folletines, pero anteriores fueron los artículos de costumbres, un género periodístico de gran importancia en América Latina a mediados del siglo XIX, dentro de la lucha por las modernizaciones. Luego vendrían las crónicas urbanas, la entrevista, y después, ya en la segunda mitad del siglo XX, los grandes reportajes bajo la influencia de notables escritores estadounidenses (Capote, Mailer). Son estos (crónica, entrevista, reportaje), tal vez, vistos desde la actualidad, los grandes géneros del periodismo.

8 Sobre los periódicos chilenos en el siglo XIX, Carlos Ossandón, El crepúsculo de los sabios y la irrupción de los publicistas. Santiago, Universidad Arcis y LOM Ediciones, 1998.

9 Susana Rotker, La invención de la crónica. Buenos Aires, Ediciones Letra Buena, 1992, p. 94. "En 1877 el número de diarios que había era de 148, para 2.347.000 habitantes, es decir, uno por cada 15.700 habitantes: Estados Unidos apenas duplicaba esa cifra". 
Desde luego, Joaquín Edwards comienza a escribir crónicas en un determinado momento de la historia latinoamericana del género. Susana Rotker, en un ensayo premiado en el concurso Casa de las Américas, Cuba, en 1991, se hace cargo de esta historia y da como objeto específico de su ensayo los orígenes del género, asociados a los textos publicados, hacia fines del siglo XIX, por José Martí, primero en La Opinión Nacional de Caracas, y luego en La Nación de Buenos Aires. Por supuesto, no podría abordar su tema sin asumirlo necesariamente ligado a la historia del periódico, de la que entrega información importante. Junto con articular la función de los periódicos a la misión "racionalizadora" de la modernidad (término conceptual de Max Weber, retomado por Ángel Rama en La ciudad letrada), y sumar a esa función la de la crónica, Rotker ofrece análisis valiosos en su reconstrucción de la fase inaugural de la historia de la crónica. Además de postular la tesis según la cual la crónica de fines del XIX que ella examina, la de Martí (y también Darío, Nájera) tendría un papel decisivo en la formación misma de los modos estilísticos del lenguaje poético del "modernismo", en su movimiento crítico va proponiendo definiciones de la crónica que tal vez de pronto podrían resultar insuficientes, o muy parciales, incluso dispersas, pero que de todas maneras representan avances importantes en el proceso de fijar la historia y las particularidades del género (Rotker 85, 96, 113).

Sin periódico, históricamente, no hay crónica urbana. Pero para la crónica (como para los demás géneros periodísticos), el periódico no solo es el espacio propio de su inserción, sino que de él extrae, como de una matriz, algunos de sus rasgos constitutivos fundamentales, es decir, sus propiedades como género. Esta matriz se configura e interviene en dos planos: de relaciones internas en uno, y externas en el otro. En el primero, el periódico se presenta como un espacio de escritura (y de lectura), internamente regido por la discontinuidad entre los diversos textos que lo forman. Es pues un espacio regido por el fragmentarismo (el mismo que obliga al lector a seleccionar él los textos que quiere leer, el orden en que quiere hacerlo, en otras palabras, a armar su propio periódico). Como marca ostensible de su identidad de género, la crónica lleva consigo este fragmentarismo, llamémoslo estructural, del periódico: es visible en la necesaria brevedad de su texto, en lo imprevisible del tema, en el modo un poco abrupto con que se inicia y concluye. El segundo plano de configuración de la matriz, dije, introduce relaciones externas. Me refiero aquí al periódico desde el punto de vista de su lector: un lector concebido como no especializado, común, de cultura general, pero sensible a las novedades del tiempo. Este tipo de 
lector le impone al periódico como espacio de escritura el sometimiento a un principio: el de ser discursivamente "accesible" a ese lector. El lenguaje de la crónica no puede excluirse de este principio de accesibilidad. Y si hay una propuesta de "estilo" en un cronista, éste tendrá que forjarla a partir del pie forzado de la accesibilidad del lenguaje.

Edwards, en sus crónicas, no solo hace evidente su sujeción a la matriz del periódico y sus imposiciones: es al mismo tiempo perfectamente consciente de ellas, como queda a la vista en la enorme cantidad de crónicas dedicadas a su comentario ${ }^{10}$. Pero aún más: hay una circunstancia biográfica reveladora de cómo, en su caso, la condición fragmentaria del periódico no solo se impone, de la manera más ejemplar, en sus crónicas, sino que incluso el cronista la reproduce en el terreno doméstico, en el espacio de la casa donde habita, estableciéndose así una suerte de simetría entre ambas esferas (una pública, otra privada). No era fácil, se sabe, ser recibido por Edwards en su casa de Santiago. El testimonio de uno de los pocos que tuvieron ese privilegio, la periodista Lenka Franulic, que lo entrevista, describe el interior de esa casa: "Cada habitación de Santo Domingo 2315 es un archivo. En estantes, cajones y mesas hay carpetas de recortes reunidos desde hace treinta años" (García-Huidobro 145).

El archivo repite, en espejo, el orden fragmentario del periódico. Cada archivo es un depósito de documentos relativos a alguna materia, a algún tema, cualesquiera sean, entre los cuales no hay una relación de continuidad, exactamente como entre los textos de un periódico. Los textos de un archivo parecen estar cerrados sobre sí mismos, sobre su propio corte, el de sus límites, el que un poco azarosamente los separa de los demás. Separados por el corte, viven como a la intemperie, sin horizonte. Por eso, en el sentido de Benjamin, lo contrario del archivo sería la "colección", y el "coleccionista", lo opuesto del archivero. Para el coleccionista sus objetos son lo que no son los textos de un archivo: "únicos", irreemplazables, puentes entre su cercanía y la "lejanía" a que remiten. "Los coleccionistas son fisonomistas del mundo de los objetos. Es suficiente observar a uno de ellos mientras manipula las cosas de su vitrina. Apenas las tiene en la mano, parece inspirado por ellas, como un

10 Véase la colección de crónicas suyas sobre este tema, En torno al periodismo y otros asuntos. Selección, distribución y prólogo de Alfonso Calderón. Santiago, Editorial Andrés Bello, 1969. 
mago que viera a través de ellas su lejanía" (Benjamin 121-123). Son pues, en "su lejanía", objetos "auráticos". Nada más ajeno al aura que el archivo y sus objetos. Pero el aura no es moderna (la modernidad la ha expulsado, permitiéndole una suerte de sobrevida en los objetos de las colecciones), y el archivo en cambio es una clave del mundo cultural moderno, empezando por el mundo de la vida cotidiana.

$\mathrm{Si}$, históricamente, no hay crónica sin periódico, tampoco hay crónica sin la aparición de un determinado tipo de lector de periódicos: un lector habitante de ciudades cuya vida cotidiana se abra, doblemente, a la calle como su escenario de prácticas, y, desde este escenario, o en él, a la experiencia del tiempo corrosivo de la modernidad: un tiempo urbano fugaz, inestable, tiempo de promesas, fracasos y glorias efímeras, del que Marshall Berman ha ofrecido una imagen viva ${ }^{11}$. Esta experiencia del tiempo, que en Europa era ya un supuesto de la sensibilidad y el pensamiento de Baudelaire a mediados del siglo XIX, en América Latina solo comienza a dar testimonio de sí cincuenta años después, desde fines del siglo XIX, es decir, cuando terminan instalándose (en algunas capitales y ciudades-puertos) escenarios de vida que la hacen posible. Si a esos años, como lo establece la investigación de Rotker, remiten los orígenes de la crónica, es justamente porque entonces comienza a existir el lector que la crónica necesita, con el que puede sintonizar, y porque también es entonces cuando comienza a configurarse la clase de vida cotidiana que lo incluye.

Edwards tuvo, desde el principio, un grado realmente excepcional de conciencia de, por un lado, la naturaleza de este tiempo de la modernidad cotidiana y, por otro, de la condición de la crónica como una suerte de espejo suyo a nivel de su escritura y de sus propiedades de género discursivo. Para el lector actual, las manifestaciones de esa conciencia, constantes y múltiples, convierten efectivamente a la crónica en una verdadera metáfora del tiempo de la modernidad. Edwards habla de pronto del periodista como si ser periodista significara ser por ese solo hecho un cronista, y, al revés, como si ser cronista no fuera sino un modo de ser periodista. Por eso puede decir del periodista: "ve la vida como crónica". Y puesto que la práctica de la crónica, como vimos, es una práctica del tiempo siempre en fuga de la modernidad,

11 Marshall Berman, Todo lo sólido se desvanece en el aire. La experiencia de la modernidad. Traducción de Andrea Morales. Buenos Aires, Siglo XXI Editores, 1989. 
la vida de su autor, el periodista-cronista, "se convierte en borrador eterno". Nunca son pues las suyas vidas en limpio, estabilizadas: son solo vidas como "borrador". Siempre provisorias. Pero lo que dice Edwards del cronista-periodista es igualmente válido para su producción: la crónica. Como lenguaje, como género discursivo, la crónica está concebida para aprehender y dejar ver la transitoriedad del tiempo moderno: como él, "Cada crónica muere en la noche". La más viva imagen de la condición del cronista-periodista y de la crónica, la construye Edwards en esta frase metafórica: el cronista escribe su crónica "en papel de fumar" (García-Huidobro 179). Es decir, la crónica, como el periodismo, como el tiempo de la modernidad, como nuestras vidas cotidianas, es material fungible: desechable. Para graficar esta relación solidaria, de simbiosis, entre la condición de la crónica y la del tiempo de la modernidad, ambos de estricta transitoriedad, de vida pasajera, dirá que su madre no leía sus crónicas, y que incluso "Una vez un pedido de la carnicería llegó envuelto en una de mis crónicas" (García-Huidobro 194) ${ }^{12}$.

\section{CRÓNICA Y CRÍTICA DE LA VIDA COTIDIANA CHILENA}

Las crónicas de Edwards no solo contienen un registro de la vida cotidiana chilena en la primera mitad del siglo XX, sino el más vasto y lúcido que nos ha quedado de este período de la historia de nuestra modernidad. En la cotidianeidad de las prácticas culturales y políticas, del juego de roles e identidades sociales, del gesto y del discurso, de rituales y tradiciones, Edwards descubre los signos de un orden social, de un modo (el del chileno) de estar o ser en el mundo. Lee esos signos sin "sustancializar" su significado. A veces se limita a identificarlos y a describirlos de tal modo que la descripción misma sugiere las pistas de lectura. En otros casos, pone en juego códigos de lectura "desconstructores" del tramado ideológico de los signos. Estos asumen entonces la condición de signos opacos, velados, y el discurso cronístico aparece por tanto entregado a la tarea crítica de "desplegar" lo "plegado", en otras palabras, de dejarlo a la vista. Volveré luego sobre los problemas aquí insinuados, pero será en un contexto crítico menos escueto,

12 Esta frase de Edwards recuerda un dicho bastante conocido que subraya la condición efímera del periódico, aplicable igualmente a la crónica: "Con el diario de hoy se envuelve el pescado de mañana". 
definido con más amplitud. Antes quisiera argumentar brevemente acerca de cómo la destreza para descubrir los signos de que hablaba y el talento para leerlos no le llegaron a Edwards sin la mediación de circunstancias biográficas excepcionales, que contribuyeron a la adquisición de una y a la educación del otro.

Hasta los diecisiete años, la vida de Edwards transcurre en Valparaíso, un puerto abierto, después de la Independencia, a la expansión neocolonialista europea (inglesa sobre todo) y estadounidense del siglo XIX. De ambas, apertura y expansión, da testimonio el temprano desarrollo urbano de una modernidad mercantil, financiera, arquitectónica, periodística, con ramificaciones y efectos culturales múltiples. Sin duda, Valparaíso, hacia fines del XIX, en la infancia y adolescencia de Edwards, era en Chile un espacio urbano de avanzada desde el punto de vista de una vida cotidiana moderna. Como miembro de la burguesía chilena, la nueva clase social dominante, el viaje de Edwards a Europa en 1904 resultaba previsible en la medida en que se había convertido en un verdadero rito social y cultural de clase. Primero a Francia, París obviamente, luego a Inglaterra, donde estudia, y a España, a Madrid. Se quedará algunos años. En 1910, cuando se publica su novela El inútil, está de vuelta en Chile, pero no tarda en regresar a Europa. Será testigo de los acontecimientos de la Primera Guerra Mundial. Los suyos son viajes y estadías desde la condición de un aristócrata con capacidad de ocio, medios para financiarlo e intereses culturales, específicamente literarios y periodísticos (ya activos en sus años de colegio en Valparaíso), intereses éstos (inesperados, además de ingratos, a los ojos de su clase social), que deciden los lugares que frecuenta y las relaciones que establece.

Los años de Europa son de inmersión intensa, y desde una gran libertad personal, en la vida cotidiana y el tiempo de una modernidad desarrollada. Son años, diría, de aprendizaje y dominio de las claves de un orden social y cultural. También años de formación de una mirada crítica (en términos éticos, estéticos, sociales, históricos) frente a los signos culturales generados y puestos en circulación por la cotidianeidad de sociedades modernas en etapas de desarrollo avanzado, y dentro de esa cotidianeidad, por la del mundo de la burguesía aristocratizante de comienzos del siglo XX (de alguna manera también el mundo de su propia clase social), cuyo horizonte histórico se cerrará con la Primera Guerra Mundial. Quiero citar una crónica de Edwards que hace evidente esa mirada desde un escenario justamente europeo, pero en la perspectiva chilena. Me refiero a la crónica donde evoca su encuentro en Madrid con Teresa Wilms, en la década de 1920. La presenta protagonizando 
los gestos corporales, verbales, propios de una estética, la de la "belle époque", dominada sin embargo por un espíritu de rebeldía, de querer salir e ir más allá de los límites de una ética, la finisecular, y de trascenderlos poéticamente. Pero, dice Edwards, ella estaba dotada solamente con su belleza física, sin el talento literario necesario para construir la salida. Un personaje trágico que terminó naufragando (Edwards Bello 1924: 192-195). Es probable que esta crónica sea uno de los primeros entre los pocos textos sobre Teresa Wilms ${ }^{13}$, una figura cuya vida es, a pesar de sí misma, un testimonio chileno alucinado del fin de una época.

En consonancia con el volumen de la producción cronística de Edwards, de dimensiones inusuales (siguen publicándose nuevas compilaciones), sus temas son también de una variedad enorme, sosprendente hasta en un género como la crónica (anclado en la diversidad del día tras día). Es imposible no imaginar de inmediato una relación de "complicidad", de "colaboración", entre esta comprobación y aquella constatación periodística de que Edwards había convertido su casa habitación de Santiago en un verdadero rizoma doméstico de archivos. Obviamente, es una variedad pero con recurrencias: con temas a los que se vuelve, constituyéndose así distintas zonas temáticas. Precisamente, algunas de las compilaciones publicadas postulan su unidad sobre la base de que las crónicas seleccionadas se inscriben en el ámbito de tal o cual zona temática. Ahora bien, sin duda la zona mayor, la dominante, la delimitan las crónicas cuyo tema común es la sociedad chilena, su identidad, su presente, su futuro, su historia. Es también la zona comprometida en este ensayo. Pero lo es con un encuadre fuertemente reductor y con una focalización asimismo restrictiva.

He hablado antes de ese encuadre y de esta focalización. Los reformulo aquí para luego resituarlos en un marco de conceptos operativos, mínimos pero suficientes para que mi ensayo complete su anunciado recorrido. Por una parte, en este ensayo recorto la extensión de esa zona temática dominante y reduzco la problemática cultural de la sociedad chilena solo a aquellos elementos suyos que la vida cotidiana durante la primera mitad del siglo XX pone en escena y que las crónicas de Edwards registran. Pero a éste agrego un segundo recorte: dentro de las crónicas implicadas en ese registro, focalizo mi

13 Ver mi libro Carta de amor y sujeto femenino en Chile. Siglos XIX y XX. Santiago, Editorial Cuarto Propio, 2003, pp. 93 y ss. 
interés específico en aquellas donde el lector asiste al ejercicio de una crítica de la vida cotidiana chilena, más exactamente, de determinadas expresiones sociales que esta cotidianeidad escenifica. Son muchas esas crónicas y están, la mayoría, dispersas en las diversas colecciones publicadas. Ahora bien, el conjunto de crónicas agrupables en torno al tema de la crítica de la vida cotidiana chilena, internamente no constituyen un todo homogéneo desde el punto de vista de aquello de lo que hablan: del sujeto de las prácticas culturales de la vida cotidiana y del espacio social en que ellas ocurren.

No hay, decía Foucault, ningún espacio social totalmente marginado del poder, que no sea un lugar donde se pongan en juego las "relaciones de poder”. El poder nunca está afuera, ausente. Más aún: la mejor manera de estar presente el poder es cuando interviene sin que se note, como si no estuviera y las cosas fueran "naturalmente" como son ${ }^{14}$. Con respecto al espacio social de las prácticas de vida cotidiana, Michel De Certeau ha hecho una distinción conceptual de gran valor, útil además para la definición del problema de la no homogeneidad de las crónicas de Edwards que participan en la crítica de la vida cotidiana chilena, y para una reagrupación de estas crónicas. De Certeau concibe el espacio social de las prácticas de vida cotidiana como un espacio estructuralmente escindido, escisión que a nivel del sujeto se traduce en la necesidad de una oposición entre sujeto usuario y sujeto propietario. El usuario (el "consumidor" diríamos hoy) no sabe que el espacio social donde decide y tienen lugar sus prácticas de vida cotidiana es un espacio que no le pertenece en "propiedad", que es el espacio de un otro, del poder, su verdadero propietario y su rector. Tampoco sabe que en ese espacio ajeno, sus prácticas solo pueden reclamar para sí el alcance limitado de las "tácticas", poque las "estrategias", acciones y previsiones de largo alcance, son un privilegio del poder, a él le pertenecen (De Certeau 22).

El análisis de De Certeau permite, como adelanté, redistribuir las crónicas de Edwards agrupadas alrededor del tema de la crítica de la vida cotidiana chilena en dos sub-grupos. De un lado, aquellas (la mayoría) donde el cronista si bien fija su mirada crítica en sujetos y prácticas adscritos a uno u otro lado del espacio social escindido, al lado del poder o al de sus regidos, al de las

14 Es vasta la bibliografía de Foucault sobre el poder. Remito a los textos reunidos en Michel Foucault, Estrategias de poder. Obras Esenciales, Volumen II. Introducción, traducción y edición a cargo de Julia Varela y Fernando Alvarez Uría. Buenos Aires, Ediciones Paidós, 1999. 
tácticas o al de las estrategias, opta sin embargo por poner el acento (con humor, ironía, a veces hasta con irritación) en la singularidad de su modo de aparecer, en el contexto inmediato de su aparición, dejando en suspenso las condiciones de existencia de los sujetos y las de posibilidad de sus prácticas (asociadas al poder necesariamente), o dejándolas solo entrever. Las crónicas orientadas en esta dirección despliegan lo que podría llamarse una suerte de "fenomenología" de la cotidianeidad chilena o, también, una fenomenología de la "identidad" social chilena. Son las crónicas que tal vez más han contribuido a la popularidad de Edwards. A este grupo pertenecen los textos (fragmentos de crónicas) reunidos y editados en una de las colecciones póstumas, Homo chilensis ${ }^{15}$.

El segundo grupo reúne las crónicas que van más allá del simple registrar las tipicidades de la vida cotidiana en un espacio interiormente escindido, para entrar allí donde el otro, el poder que condiciona las relaciones de la vida cotidiana, se enmascara, se oculta tras sus mediaciones, y de la manera más eficaz tras sus "naturalizaciones". Son las crónicas donde la crítica de la vida cotidiana chilena se vuelve más radical, porque justamente son las que tocan fondo. En una de ellas, "En el tren presidencial", escrita en 1925, Edwards narra su viaje a Valparaíso, como periodista invitado, en el tren que lleva al presidente Arturo Alessandri, recién retornado del exilio, y a su comitiva (Edwards Bello 1964: 9-21). En los detalles del ambiente que rodea el viaje, adivinamos la agitación de un tiempo ya próximo al de nuestra propia cotidianeidad, por lo tanto un tiempo a gran distancia, a una realmente sideral, del tiempo cansino, todavía colonial, que ahogaba a Carmen Arriagada en las décadas de 1830-1850. Las escenas del viaje presidencial hablan de un tiempo de gran ritmo, dinámico, hasta atropellado. Evocan en el lector actual escenas similares del cine norteamericano ambientadas en esas primeras décadas del siglo, con "reporteros" inquietos, de gestos y movimientos tocados por el tiempo veloz de la noticia y su comunicación.

En la misma crónica, Edwards comenta el estilo oratorio y de gestión de Alessandri. Ve en él un símil del nuevo tiempo de la modernidad, de los cambios que éste exigía introducir en todos los planos del orden social. Pero el impulso renovador representado por Alessandri, que el cronista traduce

15 Selección y prólogo de Alfonso Calderón. Ilustraciones de Lukas. Valparaíso, Ediciones Universitarias de Valparaíso, 1983. 
metafóricamente en términos de "armonía musical", "orquestación", "vibración", irritó, dice, el oído del "hombre grave y estático", a quien "le convenía la inercia". Luego de algunos restos de continuidad en el sucesor de Alessandri en la presidencia (Carlos Ibáñez del Campo), se debilitará la fuerza del impulso y entonces "volverá el antiguo silencio solemne de La Moneda, que el pueblo repele ahora, por cuanto este silencio, si no está presidido por un Portales, un Balmaceda o un Montt, es funesto para la república" (20). Las palabras "grave y estático", "inercia", "silencio solemne", apuntan todas en una misma dirección de sentido: designan el poder social (político, económico, cultural). Un poder que junto con imponerse definió los privilegios de su dominio desde los comienzos mismos de la Colonia, y que ha sabido desde entonces redefinirse absorbiendo los cambios pero sin disolver su núcleo secular. Es lo que cínicamente Portales llamaba el "peso de la noche", y desde cuya tradición colonial diseñó, en la década de 1830 , el modelo originario del Estado moderno chileno ${ }^{16}$.

Edwards vuelve a tratar este tema fundamental en otra de sus crónicas, "Pobres y ricos" (Edwards Bello 1964: 167-171), escrita en la década de 1960, cuando la Revolución Cubana había triunfado en 1959 y el nombre de Fidel Castro empezaba a circular en los medios políticos de derecha como sinónimo de amenza social inminente. Edwards declara infundada esa preocupación en Chile. Como si fuera un vidente, anticipando lo que justamente ocurriría después de su muerte en 1968 (la elección de Salvador Allende y el golpe militar que derriba su gobierno en 1973), se pregunta ¿qué ocurriría en las elecciones presidenciales de 1964, si ganara "el candidato imitador de Fidel Castro"? (ese candidato era también Allende, derrotado entonces por Eduardo Frei). La respuesta terminante del cronista es: "Nada". Porque las "esperanzas" de la "mayoría" serían al final absorbidas, trituradas o amansadas

16 Otro Edwards, Alberto Edwards Vives, describe el proyecto de Portales y dice: "La obra de Portales fue la restauración de un hecho y un sentimiento, que habían servido de base al orden público, durante la paz octaviana de los tres siglos de la colonia; el hecho, era la existencia de un poder fuerte y duradero, superior al prestigio de un caudillo o la fuerza de una facción; el sentimiento era el respeto tradicional por la autoridad en abstracto, por el poder legítimamente establecido con independencia de quienes lo ejercían. Su idea era nueva de puro vieja; lo que hizo fue restaurar material y moralmente la monarquía, no en su principio dinástico, que ello habría sido ridículo e imposible, sino en sus fundamentos espirituales como fuerza conservadora del orden y de las instituciones". En su libro La fronda aristocrática en Chile. $17^{\mathrm{a}}$ ed. Santiago, Editorial Universitaria, 2005, p. 61. 
"entre las garras permanentes e invencibles que Alberto Edwards llamó la Fronda Aristocrática"17. Y agrega: "En todo el curso de nuestra historia, la clase alta conservadora, vencedora o derrotada en las elecciones, ha salido finalmente victoriosa, respirando a plenos pulmones el aire del poder vital". Estas "fuerzas conservadoras irresistibles, de atracción y de absorción" (169) constituyen, precisamente, el poder que desde Portales designamos con la frase "el peso de la noche".

Este poder oscuro, persistente, obtuso, en alianza permanente con las fuerzas armadas, cuando ha creído en riesgo real su dominio, no importa si el riesgo es local o generalizado, ha reaccionado siempre de manera brutal, justamente poniendo en acción cada vez su brazo armado: la matanza de obreros y sus familias en la Escuela Santa María de Iquique, en 1907, el golpe militar de 1973, la dictadura criminal que introdujo y que se mantuvo durante diecisiete años, son dos ejemplos extremos del siglo XX, los más conocidos por su impacto nacional o internacional. Pero cuando el horizonte aparece despejado, sin nubarrones, ese mismo poder, seguro ya de sí, se repliega como fuerza bruta y deja que actúen sus discursos, naturalmente ideológicos, es decir, opacos, embozados, entregándoles la tarea de asegurar, de mantener por otras vías (ya no traumáticas) el condicionamiento subyacente del juego de las prácticas de la vida cotidiana. En otras palabras, de darle al sujeto social para su ejecución, como si de verdad fuera suya, escrita por él, una partitura escrita por el poder.

La crítica de Edwards a la vida cotidiana chilena y al espacio social escindido que la enmarca, o la sostiene, alcanza, me parece, un momento de iluminación máxima con su crónica de 1962 "Habló el roto chileno" (Edwards Bello 1964: 265-268). Aun cuando este texto es de la década de 1960 , la figura del "roto" atrajo la atención de la mirada crítica del cronista desde muy temprano, desde los comienzos de la década de 1920 (además de convertirlo en el protagonista de una de sus novelas, titulada justamente $\mathrm{El}$ roto y publicada en 1920). ¿Quién es el "roto"? La palabra no designa a un individuo sino a un colectivo: con ella se nombra a la clase social sometida al poder. Es un sinónimo de "pueblo". En el uso chileno, la palabra tiene connotaciones despectivas, física, cultural y éticamente. El mismo Edwards,

17 Se refiere al libro de Alberto Edwards Vives, La fronda aristocrática en Chile, ya citado (publicado por primera vez en 1928). 
en una extensa crónica también de la década del 20, "No existe homogeneidad de la raza" (Edwards Bello 1924: 111-124), habló de los orígenes coloniales de la palabra roto como nombre de la clase subordinada y del abismo existente entre ella y la clase dominante, aristocrática, de tal profundidad que en lugar de clases habla de "castas".

El texto de la crónica que aquí interesa, "Habló el roto chileno", es particularmente feliz por los componentes escénicos que introduce, inseparables de su crítica. En efecto, el roto que el cronista hace hablar, habla en un lugar público particular: en una plaza, lugar tradicional de convergencia de transeúntes, asociado a celebraciones y rituales ciudadanos, escenario también de la palabra del loco y de los predicadores populares. Todo lo cual es coherente con quien efectivamente habla en esta crónica: la estatua del roto chileno, levantada en la Plaza Yungay de la ciudad de Santiago. Como toda estatua erigida en una lugar público, la del roto representa o apela a valores que deberían preservarse en la memoria. Pero, ya lo vimos, el espacio social es un espacio escindido. ¿Qué lugar ocupa lo que representa la estatua del roto desde el punto de vista de la escisión? El cronista nos dice que esta estatua ha sido erigida por la "clase alta conservadora" en homenaje al roto. ¿Un puente de unidad entre los dos lados de la escisión? Mejor: un gesto con el que la "clase alta conservadora" intenta borrar la existencia misma de la escisión, actuando como si no estuviese involucrada en lo que la estatua del roto representa, como si lo representado fuera una producción libre del roto, unos valores que, con su gesto, la "clase alta conservadora" asume como propios y los consagra públicamente como patrimonio de una sociedad (la que así estaría dando testimonio de su "unidad"). El discurso que Edwards pone en la boca estatuaria del roto revela en el cronista un claro saber acerca de las sutilezas, encubrimientos, supercherías y funciones culturales que las estrategia del poder diseminan en la vida cotidiana.

Las supercherías incluyen un detalle verdaderamente descarado. Resulta que el autor de la estatua, Virgilio Arias, hijo de chileno pero nacido en París, donde vivía, la esculpió por encargo, y le dio a los rasgos faciales del roto, en vez de los mestizos, que le correspondían propiamente, unos de aspecto más bien "afrancesado", incluso parecidos a los de un muchacho pintado por Delacroix en un cuadro sobre las barricadas de París en 1848. Lo que nos pone de inmediato en la función meramente ideológica de la estatua y del homenaje que representa, una función que el discurso del personaje irá dejando al descubierto en su despliegue. Dos afirmaciones son centrales en su movimiento "desconstructor". Una: "Me acostumbré a pensar como roto" 
(266). Esa es precisamente una de las estrategias del poder: que las relaciones sociales que induce en la vida cotidiana, que los roles que distribuye, sean aceptados como naturales, como parte del ser chileno. Y esa es por lo demás la función propia de todos los discursos a su servicio: la de persuadir a los dominados que asuman como propia, como si ellos mismos, libremente, la hubiesen construido, la identidad social que el poder, en su distribución de roles, les asigna. El roto es una de estas identidades funcionales al poder en la sociedad chilena, es decir, al "peso de la noche". En otras palabras, el roto, como identidad social, creada, celebrada y homenajeada con una estatua, es una "ficción". Así lo dice en la segunda afirmación crucial dentro del discurso del personaje: "Soy un mito, una ficción, una incoherencia social, un pretexto (...). Soy un mito usado y sacrificado en los momentos patéticos, despreciado y alejado en los momentos de paz social" (266).

Resumiendo, cuando en la historia de la sociedad chilena comienza a hacerse posible la experiencia del tiempo vivo de la modernidad, y, paralelamente, a hacerse posible el género periodístico que se nutre de ese mismo tiempo, la crónica, Joaquín Edwards Bello, el gran cronista de la vida cotidiana chilena en esa primera mitad del siglo XX, no solo registra su fenomenología sino que lleva a cabo, con una lucidez excepcional, con recursos verbales inagotables, y con una constancia de misionero, la crítica de esa vida cotidiana desde el punto de vista de lo que la condiciona, es decir, del poder que rige el espacio y las reglas del juego de las relaciones cotidianas. "Habló el roto chileno", en este sentido, es una crónica paradigmática.

\section{BIBLIOGRAFÍA}

Anderson, Benedict. Comunidades imaginadas. Traducción de Eduardo Suárez. México: Fondo de Cultura Económica, 1993.

Benjamin, Walter. “Alabanza de la muñeca”. Escritos. La literatura infantil, los niños y los jóvenes. Traducción de Juan J. Thomas. Buenos Aires: Ediciones Nueva Visión, 1989. 119-130.

Berman, Marshall. Todo lo sólido se desvanece en el aire. La experiencia de la modernidad. Traducción de Andrea Morales. Buenos Aires: Siglo XXI Editores, 1989.

De Certeau, Michel. La invención de lo cotidiano. I. Artes de hacer. Traducción de Alejandro Pescador. México: Universidad Iberoamericana, 2000.

Edwards Bello, Joaquín. Crónicas reunidas (I) 1921-1925. Edición a cargo de Roberto Merino. Santiago: Ediciones Universidad Diego Portales, 2008. 
Crónicas. Santiago: Empresa Editora Zig-Zag, 1964.

En torno al periodismo y otros ensayos. Selección, distribución y prólogo de Alfonso Calderón. Santiago: Editorial Andrés Bello, 1969.

Homo chilensis. Selección y prólogo de Alfonso Calderón. Ilustraciones de Lukas. Valparaíso: Ediciones Universitarias de Valparaíso, 1983.

Edwards Vives, Alberto. La fronda aristocrática en Chile. 1928. Santiago: Editorial Universitaria, 2005.

Foucault, Michel. Estrategias de poder. Introducción, traducción y edición a cargo de Julia Varela y Fernando Álvarez. Barcelona: Ediciones Paidós, 1999.

García-Huidobro, Cecilia. (Ed.). Joaquín Edwards Bello. Un transatlántico varado en el Mapocho. Santiago: Aguilar-El Mercurio, 2005.

Morales, Leonidas. Carta de amor y sujeto femenino en Chile. Siglos XIX y XX. Santiago: Editorial Cuarto Propio, 2003.

Ossandón, Carlos. El crepúsculo de los sabios y la irrupción de los publicistas. Santiago: Universidad Arcis y Lom Ediciones, 1998.

Romero, José Luis. Latinoamérica. Las ciudades y las ideas. 1976. Buenos Aires: Siglo XXI Editores, 2004.

Rossell, Milton. "Joaquín Edwards Bello". Atenea. Concepción. Año XLV, tomo CLXVIII, $\mathrm{N}^{\circ} 419$, p. 5.

Rotker, Susana. La invención de la crónica. Buenos Aires: Ediciones Letra Buena, 1992.

Villalobos, Sergio. Origen y ascenso de la burguesía chilena. $4^{\mathrm{a}}$ ed. Santiago: Editorial Universitaria, 1998. 